\title{
Desregulación urbanística del suelo rústico en España. Cantabria y Extremadura como casos de estudio'
}

\author{
Víctor Jiménez Barrado², Carmen Delgado Viñas ${ }^{3}$ \\ y Antonio-José Campesino Fernández ${ }^{4}$
}

\begin{abstract}
RESUMEN
La proliferación de viviendas en el suelo rústico ha tenido un fuerte impacto sobre el territorio, especialmente agudo durante las últimas dos décadas. Mediante el estudio de casos en dos regiones españolas (Cantabria y Extremadura) revelamos las diferentes particularidades que muestra este fenómeno, contrastando las dispares maneras de afrontarlo. Las tendencias compartidas hacia la desregulación de esta clase de suelo quedan evidenciadas en el estudio realizado sobre las modificaciones legislativas de corte "flexibilizador" y los procesos de legalización en ambas Comunidades Autónomas. Por último, aportamos ideas encaminadas a resolver el problema, entre las que destacan la redistribución de las competencias en materia de urbanismo. La prolongada inacción de los gobiernos para mantener la disciplina urbanística ha posibilitado las agresiones al territorio del que deberían ser custodios, por lo que es acuciante la confrontación del hecho y sus consecuencias para evitar que aumente su magnitud y complejidad.
\end{abstract}

Palabras clave: Desregulación urbanística, dispersión urbana, legislación urbanística, suelo rústico, urbanización ilegal.

\begin{abstract}
The proliferation of housings on the rural land has had a strong impact on the territory, particularly strong over the past two decades. By studying cases in two Spanish regions (Cantabria and Extremadura) we reveal the different characteristics that this phenomenon shows, contrasting the disparate ways of facing it. The shared trends towards the deregulation of this type of land are evidenced in our study of the "flexibilizing" legislative changes and the processes of legalization in both Autonomous Communities. Finally, we contribute ideas aimed at solving the problem, among which the redistribution of planning responsibilities. The prolonged inaction of governments to keep planning discipline has enabled attacks to territory which they should be stewards, so it is urgent the confrontation of the fact and its consequences to avoid increasing its magnitude and complexity.
\end{abstract}

Keywords: Urban deregulation, urban sprawl, urban planning legislation, rural land, illegal urbanization.

Esta investigación ha sido financiada por el Ministerio de Educación, Cultura y Deporte, a través del Programa de Formación del Profesorado Universitario (FPU). Referencia FPU13/00990. Artículo recibido el 13 de mayo de 2016, aceptado el 23 de septiembre de 2016 y corregido el 16 de enero de 2017

Departamento de Arte y Ciencias del Territorio, Universidad de Extremadura (España).E-mail: victorjb@unex.es

Departamento de Geografía, Urbanismo y Ordenación del Territorio, Universidad de Cantabria (España).E-mail: carmen.delgado@unican.es Departamento de Arte y Ciencias del Territorio, Universidad de Extremadura (España).E-mail: acampesi@unex.es 
La superación del debate dicotómico entre lo urbano y lo rural ha situado a los geógrafos ante el desafío de comprender y analizar los nuevos procesos de expansión urbana y el espacio sobre el que se desarrollan. Este avance, dentro de la discusión tradicional, ha derivado del nacimiento de una realidad física definida por su carácter transitorio entre dos naturalezas distintas. La interfase urbano-rural, de difícil conceptualización y, por lo tanto, de complicada delimitación espacial precisa, se plantea ahora como un problema de gestión dentro de un mundo dominado por la necesaria reglamentación y conciliación de usos del suelo. La compleja demarcación de este ámbito geográfico ha suscitado importantes inconvenientes para las Administraciones encargadas de gestionar la materia y práctica urbanísticas. Estas dificultades han resultado particularmente relevantes en España, donde el esquema reglamentario atiende a patrones muy rígidos. La zonificación urbanística de los términos municipales, que comprende la atribución de diferentes regímenes urbanísticos en función de las distintas clases de suelo, y que fue incluida en el planeamiento desde la primera Ley del Suelo de 1956 por influencia de la legislación italiana, ha enfrentado un modelo teórico disciplinado con un proceso real guiado por una nueva forma de ocupar el espacio, desligada de las limitaciones espaciales y morfológicas que fija la norma. Este modelo de planificación, basado en el establecimiento de límites de ideación perfecta (correspondencia exacta entre la realidad territorial y la división impuesta por la Administración) y de materialización obligadamente imperfecta, por la imposibilidad de subdividir el territorio desde una perspectiva holística, empuja al sistema español hacia un resultado final disfuncional, debido a la aparición de fenómenos no contenidos en la previsión y/o al cambio de comportamiento humano. La precedencia y prevalencia que Baudrillard (1978) otorgó al mapa sobre el territorio, sobredimensionó ilusoriamente la capacidad gestora de las Administraciones (o la voluntad política de los gobernantes) y sobrevaloró la actitud disciplinada de la sociedad para con la norma. A pesar de ello, este sistema resulta el más idóneo, pues garantiza (siempre que se mantenga la disciplina) un desarrollo urbano dimensionado y localizado bajo parámetros lógicos y sostenibles extraídos de un ejercicio técnico de primer nivel que lo justifica. No obstante, y a tenor de lo dicho, el sistema precisa de correcciones que vengan a conciliar las nuevas formas de crecimiento con el modelo propuesto anteriormente.

Estos nuevos procesos de expansión urbana, cuyo germen fue descrito y conceptualizado por Berry (1976) bajo el término contraurbanización, y que desde entonces han evolucionado en otras muchas variantes, ponen de manifiesto una renovada apetencia por lo rural, esta vez no con la consideración tradicional de espacio productivo sino contemplando un uso residencial total o parcialmente descontextualizado de las actividades rurales tradicionales. El trasvase demográfico desde la ciudad al campo, a veces desordenado, provoca una fuerte impronta sobre el territorio por la llegada de nuevas formas de vida sobre un espacio geográfico modelado por la funcionalidad productiva. Así, dos paradigmas coinciden en un solo espacio, haciendo que el territorio se configure como un palimpsesto (Corboz, 2004), es decir, los usos se superponen y mezclan en el territorio sin que necesariamente exista una sustitución completa de unos por los otros, lo que genera a su vez tensiones de difícil resolución, pero que en el caso que nos atañe suelen resolverse a favor de la colonización de lo rural por lo urbano. El avance urbano se conforma como un reemplazo incompleto de usos y actividades por su discontinuidad espacial y temporal, resultando una infiltración urbana (Naranjo, 2009) en el mundo rural, que además escapa de los parámetros que fija la planificación urbanística.

Los procesos de ocupación irregular de los terrenos rústicos (es decir, aquellos en los que ni se permiten los usos urbanos ni deberían estar presentes), denominados por la legislación urba- 
nística cántabra como "suelo rústico" y por la legislación urbanística extremeña como "suelo no urbanizable", han traspasado el ámbito urbanístico y se establecen ya como uno de los principales problemas de índole social y territorial en todo el mundo. Sin embargo, este fenómeno presenta particularidades según su localización en razón de su magnitud, emplazamiento, impacto y responsabilidad. No obstante, uno de los factores definitorios de las características del hecho, y que está en la raíz del fenómeno, es el nivel socioeconómico de sus protagonistas, lo que se traduce en asentamientos irregulares de características muy distintas en atención al elemento desencadenante: necesidad versus oportunidad. En este sentido, en América Latina este tipo de crecimientos está vinculado esencialmente a espacios periféricos y marginales de las grandes metrópolis "como la alternativa usual para aquellos que no poseen los recursos suficientes" (Mosquera y Ahumada, 2005: 14) y que encuentran su contrapunto en las "ciudades valladas" para las altas clases sociales (Borsdorf e Hidalgo, 2005), conformando un modelo en el que los rápidos crecimientos poblacionales de las urbes llevan asociados fenómenos de segregación socio-espacial (Castagna et al., 2010). Sin embargo, el crecimiento urbanístico irregular también se encuentra en los entornos rururbanos de países europeos, donde "el modelo se fundamenta en una fuerte demanda residencial de élites socio-económicas de orígenes diversos con un nexo en común: que huyen de la ciudad" (Galacho, 2011: 268). En el primer caso, de forma general, estaríamos hablando de grandes conjuntos de infraviviendas que constituyen primeras residencias para los estratos sociales más bajos, mientras que en el segundo ejemplo, se trataría de la proliferación de residencias habituales o secundarias en espacios periurbanos o plenamente rurales, en contraposición al modelo de vida en la ciudad, que generan "un elevado consumo de suelo, derivado de las morfologías de baja densidad por las que se opta y que se justifican por el intento de integrar las nuevas urbanizaciones en espacios de carácter rural" (Ainz et al., 2011: 373), fenómeno bien conocido en los países centroeuropeos donde la ciudad se proyecta fragmentada sobre el medio rural (De Miguel, 1994).

En España, además, entran en juego tres aspectos fundamentales que han condicionado este fenómeno: uno de tipo estructural, ligado a la distribución de competencias en materia de ordenación territorial y urbanismo entre el Estado y las Comunidades Autónomas; otro de tipo coyuntural, referido al periodo de expansión económica experimentado por España en los inicios del siglo XXI, y por último, uno de tipo ideológico, pues el modelo neoliberal ha promocionado la desregulación del suelo como herramienta para alcanzar un paradigma de crecimiento socioeconómico ilimitado. Partiendo de esta triada de condicionantes, las preguntas planteadas en este estudio son: ¿es cierta la premisa de que existe en España una flexibilización galopante del uso urbanístico de los terrenos rurales? Si así fuera, y tomando como ejemplo regiones tan disímiles desde el punto de vista territorial y urbanístico como Cantabria y Extremadura, ¿cómo han articulado, y bajo qué términos y herramientas, esta progresiva desregulación los gobiernos competentes en materia urbanística y territorial?

Por tanto, nuestro objetivo principal es demostrar el proceso liberalizador del suelo en España, a través del estudio de dos regiones, para lo cual analizamos sus respectivos marcos legales y sus recientes modificaciones ad hoc, que a priori han favorecido una mayor ocupación de los terrenos rurales por parte del uso residencial. Para el estudio de los casos concretos hemos acudido al análisis de los instrumentos de planeamiento urbanístico, a través de consulta directa de la documentación original en las sedes de las Administraciones regionales o mediante sus sistemas de información territorial. 
La expansión urbana es un hecho constatado y sus consecuencias han sido ampliamente expuestas por innumerables autores y administraciones, sirviendo de ejemplo el informe de la Comisión Europea del año 2006 titulado "Urban sprawl in Europe. The ignored challenge". Sin embargo, sus características son muy heterogéneas. Sin anticipar demasiado los elementos que definen el fenómeno en cada caso, la región extremeña presenta un modelo de ocupación eminentemente clandestino y con gran protagonismo de viviendas dispersas y agrupamientos de tipo mediano (200-300 viviendas), mientras que en Cantabria predomina la construcción de urbanizaciones amparadas por una normativa no ajustada a legalidad, aunque generalmente bien conectadas con el suelo urbano (SU) y provistas de servicios.

\section{La expansión urbana y su expresión en el contexto de las regiones españolas}

La ocupación del "suelo no urbanizable" o del "suelo rústico" por parte de la edificación destinada a vivienda debería ser un hecho excepcional, como así recoge la legislación española. Sin embargo, durante las últimas décadas, el desacato a la norma se ha producido, y se mantiene, por lo que la urbanización difusa está alterando el territorio. La expansión de las grandes ciudades a nivel mundial se manifiesta ahora mediante un "movimiento espacial centrífugo hacia la periferia, en condiciones de baja densidad" (Brain et al., 2010: 113), urgiendo la necesidad de nuevas políticas de planificación urbanística para regular estos crecimientos.

Este fenómeno de expansión de lo urbano engloba otros como la suburbanización, entendida como el progresivo abandono del "centro de la región metropolitana,..., en favor de localizaciones más periféricas" (García-López, 2012: 55), la rururbanización, "proceso de urbanización de espacios rurales;..., lo cual origina formas híbridas entre lo rural y lo urbano" (Gómez, 2010: 115) y la periurbanización, descrita como la "difusión de funciones desde un polo urbano al área rural más próxima" (Delgado, 1999: 93). Cabe denotar que, aun siendo conceptos ampliamente asentados, su utilización en contextos escalar y espacialmente distintos produce alteraciones entre la noción local y particular de los mismos y la expresión real observada. De ahí que resulte interesante enmarcar las particularidades percibidas en el caso español. En primer lugar, conviene no abstraerse de la condición social de sus protagonistas, lo cual determina las variadas realidades del problema, y por lo tanto, la conceptualización y caracterización de las mismas, bien estudiada por Canestraro (2013). Así, cabe hacer una importante diferenciación entre el concepto clásico de periferia empleado en países desarrollados europeos y el utilizado en algunos países latinoamericanos. En éstos últimos se define este espacio como "la circunferencia externa a la ciudad en la cual están los pobres, los dominados, los despojados" (Hiernaux y Lindón, 2004: 111) que genera varias "subciudades", a través de procesos de segregación social y morfológica (Valenzuela, 1999). Así, en el contexto latinoamericano "la marginalidad de estos sectores es un factor preocupante puesto que genera condiciones indignas de vida para sus habitantes" (Vargas, 2014: 58), mientras que, en el contexto europeo que aquí estudiamos, el concepto de periferia está marcado por una consideración positiva de partida y exenta de problemáticas como la exclusión social. La mayor transversalidad socioeconómica de sus pobladores, que irrumpen en la periferia rural como parte de la consecución de un hito económico (vivienda secundaria o residencia principal con mejores características), dificulta la desarticulación social de estos espacios. De este modo, mientras en Latinoamérica la proliferación de asentamientos irregulares está ligada a la combinación de 
rápidos crecimientos urbanos y bajos niveles de renta entre los migrantes que protagonizaron el éxodo rural (Da Penha et al., 2014), en España, el aumento de la calidad de vida en los espacios rurales, gracias a los avances tecnológicos y al desarrollo de las vías de comunicación, ha sido clave para que el uso residencial se expanda y sustituya a una actividad agraria que cada vez ocupa menos espacio y es menos rentable para los pequeños productores.

La legislación urbanística de las Comunidades Autónomas españolas define el "suelo no urbanizable", o "suelo rústico" en algunos casos, como aquella categoría de suelo preservada de la construcción, ya sea por pertenecer al dominio público, por los valores que contiene o por no parecer adecuada para tal fin. No obstante, todos los marcos normativos permiten la construcción de viviendas, siempre y cuando se respeten los parámetros fijados para cada categoría de suelo. Traspasar estos límites supondría la desnaturalización, en el sentido más amplio y multívoco de la palabra, de esta clase de suelo. A pesar de ello, varias Comunidades Autónomas españolas están suavizando sus normas para permitir un mayor aprovechamiento residencial del "suelo rústico", un hecho ya acaecido en el contexto sudamericano (Hidalgo y Zunino, 2011: 81) para dar cabida al crecimiento residencial, lo cual ha beneficiado mayoritariamente a las clases altas ${ }^{5}$.

Los marcos normativos en materia de urbanismo y ordenación territorial de Extremadura y Cantabria, los cuales son prácticamente coetáneos, han sido modificados en varias ocasiones (al menos 3 de forma expresa) en un intento claro de flexibilizar los usos permitidos en el "suelo no urbanizable" y en el "suelo rústico". Estas tentativas han chocado repetidas veces con cuerpos normativos de rango superior y/o prevalentes, como aquellos destinados a la protección del medio ambiente, y en consecuencia, con los Tribunales Superiores de Justicia de ambas comunidades e incluso con el Tribunal Supremo (TS) del Estado español.

La urbanización del denominado "suelo rústico" en Cantabria, y "suelo no urbanizable" en Extremadura, presenta diferentes características y motivaciones. En primer lugar, la región cántabra posee un elemento de atracción que aumenta la magnitud del fenómeno: el litoral. Esta Comunidad Autónoma cuenta con 284 kilómetros de costa, ocupados en buena medida por edificaciones destinadas al turismo residencial (Delgado, 2008). De su gran potencial turístico y la proximidad de una metrópoli como Bilbao (en la vecina Comunidad Autónoma del País Vasco), se deduce el protagonismo que la población foránea de origen vasco adquiere en este fenómeno, parte de la cual ha llegado a establecer su residencia principal en Cantabria, fundamentalmente en la parte costera oriental, donde "la autovía rompió las limitaciones que imponía el tiempo de desplazamiento,....de manera que la presión de esta ciudad se deja sentir con nitidez" (García, 2002: 242). En Extremadura, la influencia clara de una gran metrópoli sólo se aprecia en el norte de la región. Las zonas más próximas a Madrid son, además, las que tienen un mayor atractivo turístico fundamentado en sus valores naturales y paisajísticos. Las comarcas del Valle del Jerte - La Vera son incipientes destinos turísticos de interior donde las segundas residencias, a veces de lujo, salpican el medio rural. En el resto de Extremadura, los principales protagonistas de la ocupación del "suelo no urbanizable" se identifican con la población autóctona o aquellos inmigrantes retornados por cortos periodos vacacionales (fin de semana). Las particularidades propias de cada región tienen el denominador común de constituir un desarrollo urbano irregular en

En Chile, el Decreto con Fuerza de Ley n 3516 de 1980 permitió la subdivisión del suelo rústico en predios de 5.000m², rebajando así las exigencias de reparcelación con fines residenciales. 
terrenos rurales que no sólo no ha encontrado confrontación en la Administración, sino que ésta, además, ha facilitado su prolongación gracias a las modificaciones del planeamiento urbanístico y la flexibilización de los marcos normativos.

\section{La urbanización del "suelo rústico" cántabro y del "suelo no urbanizable" extremeño}

La incesante construcción de viviendas durante la burbuja inmobiliaria incrementó notablemente la expansión urbanizadora en nuestro país, algo que, sin embargo, tuvo un "escasísimo cuestionamiento por parte de los principales partidos políticos, que con contadas excepciones apoyaron sin reserva la formidable y desmesurada expansión urbana" (Gaja i Díaz, 2015: 19). Cantabria y Extremadura presentan numerosos ejemplos (Figura $N^{\circ} 1$ ):

Figura No 1

Localización de los casos de estudio en Cantabria y Extremadura.

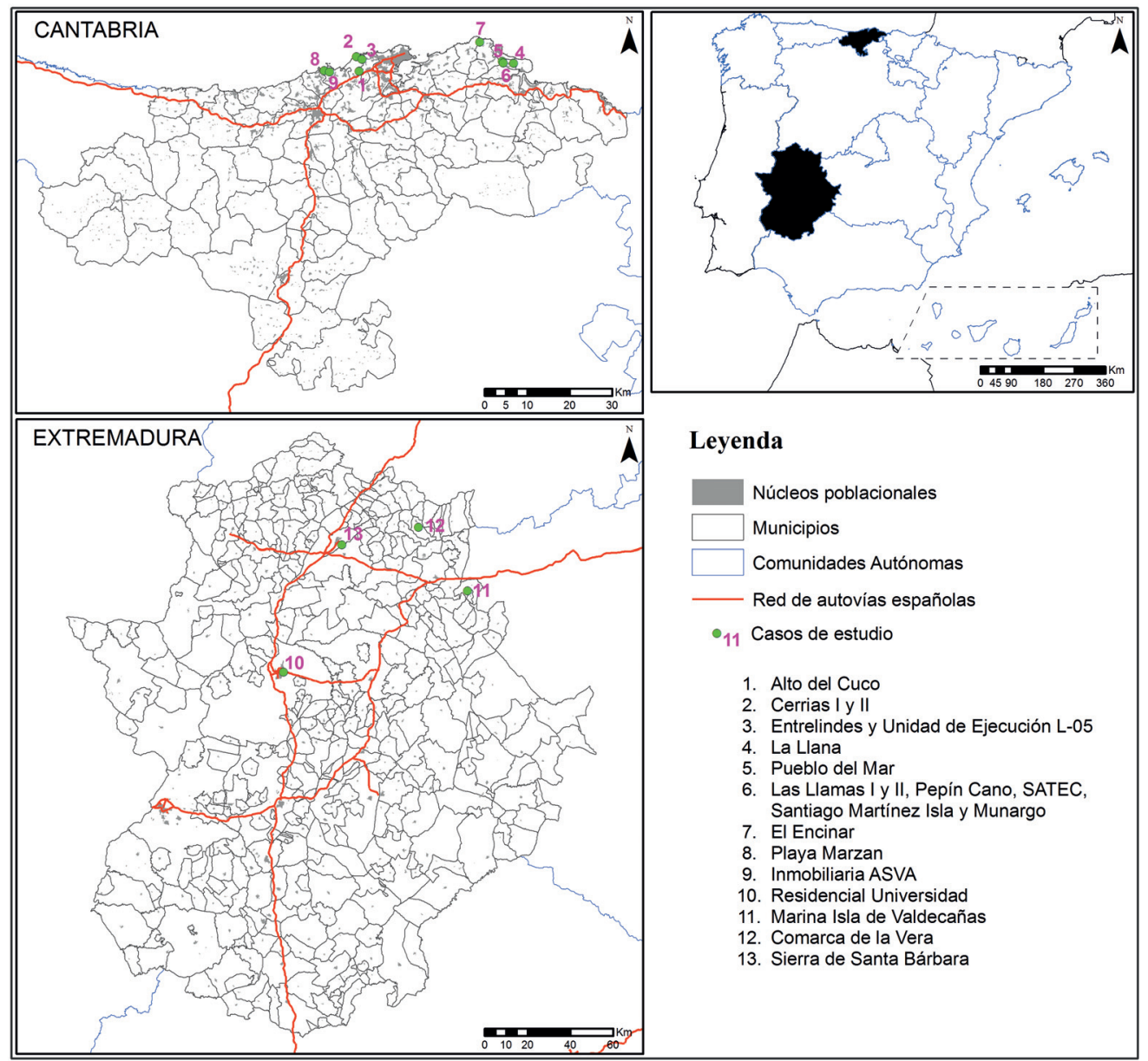

Fuente: Elaboración propia. 


\section{Urbanización "planificada" sobre "suelo rústico". El caso cántabro}

La Comunidad Autónoma de Cantabria, dentro del contexto español, es una pequeña región litoral $\left(5.321 \mathrm{~km}^{2}\right)$ intensamente poblada (582.206 habitantes), pues su densidad de población $\left(109,42 \mathrm{hab} . / \mathrm{km}^{2}\right)$ supera en casi 20 unidades los valores medios nacionales. Su sistema de poblamiento se reparte entre núcleos compactos y asentamientos dispersos, éstos últimos debidos a su carácter montañoso y a los aprovechamientos productivos tradicionales del territorio. En la actualidad, Cantabria se encuentra en un proceso acelerado de concentración urbana, pues sólo cinco municipios reúnen más de la mitad de la población regional, teniendo su capital, Santander, un peso demográfico más que notable, ya que aglutina prácticamente el $30 \%$ del total de la población cántabra. La presencia del litoral ha constituido un elemento de atracción para la población foránea que ve en esta región un espacio idóneo para el disfrute de su tiempo de ocio, algo que en muchos casos viene acompañado de la construcción de segundas residencias. En relación con esto, tienen una relevancia notable las promociones de viviendas enclavadas en terrenos de alto valor ecológico y cercanos a la costa, donde las empresas promotoras nacionales y regionales establecieron su espacio de negocio durante el periodo de crecimiento inmobiliario acelerado.

Figura $\mathrm{N}^{\circ} 2$

Construcción de la Urbanización Costa Verde en el municipio de Piélagos (2002-2014)
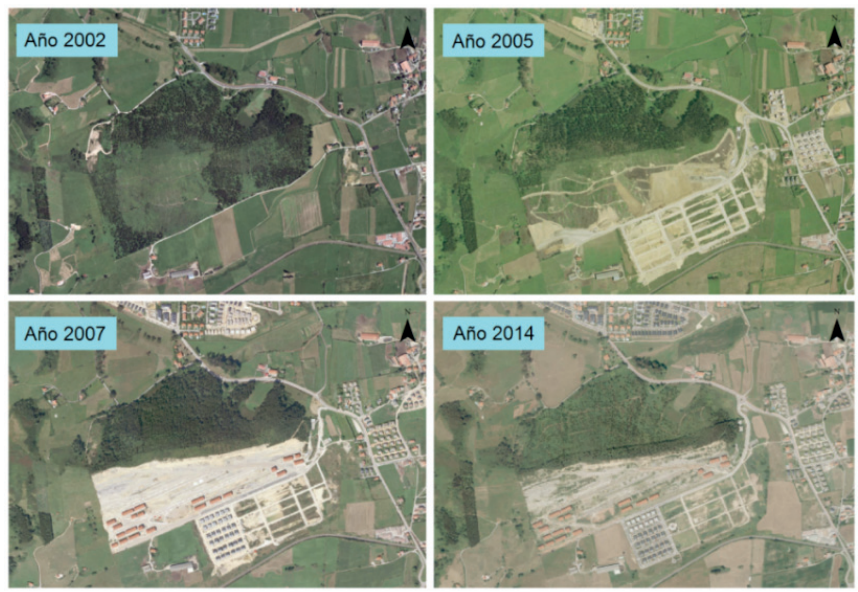

Fuente: Elaboración propia a partir de las ortofotografías del Instituto Geográfico Nacional.

Uno de los enclaves más paradigmáticos, en su vertiente negativa, fue la Urbanización Costa Verde (Figura $\mathrm{N}^{\circ} 2$ ), situada en la zona del Alto del Cuco, perteneciente al término municipal de Piélagos, que, según el informe Banderas Negras elaborado en 2007 por una asociación ambientalista denominada Ecologistas en Acción, es el municipio con más amenazas detectadas sobre el litoral de Cantabria. Dicha urbanización ha sido derribada a finales de 2016 gracias a la Sentencia del Tribunal Superior de Justicia de Cantabria (TSJC) de 2007, tras repetidos intentos del municipio de Piélagos para evitar la demolición de las obras mediante recursos a los tribunales. Este proyecto concebía la construcción de 395 viviendas sobre la ladera meridional del Monte La Picota, que fue desmontada enteramente. El Ayuntamiento dio el visto bueno definitivo al proyecto, basándose en un informe favorable de la Consejería de Medio Ambiente (administración competente en materia medioambiental), aunque desoyendo el informe desfavorable de la Comisión 
Regional de Urbanismo (órgano consultivo). Además, su aprobación fue inmediatamente anterior a la aprobación del Plan de Ordenación del Litoral (POL) de Cantabria ${ }^{6}$, para evitar que éste pudiera interferir en el proyecto, ya que "en su primera redacción, protegía cómo área de interés paisajístico los terrenos" (Delgado, 2010: 478). Fue precisamente el impacto paisajístico generado lo que motivó la denuncia de las asociaciones ecologistas, la cual derivó en la posterior sentencia de demolición de las aproximadamente 200 viviendas que llegaron a construirse finalmente.

Figura $\mathrm{N}^{\circ} 3$

Construcción de las urbanizaciones Cerrias I y Cerrias II (1988-2014).
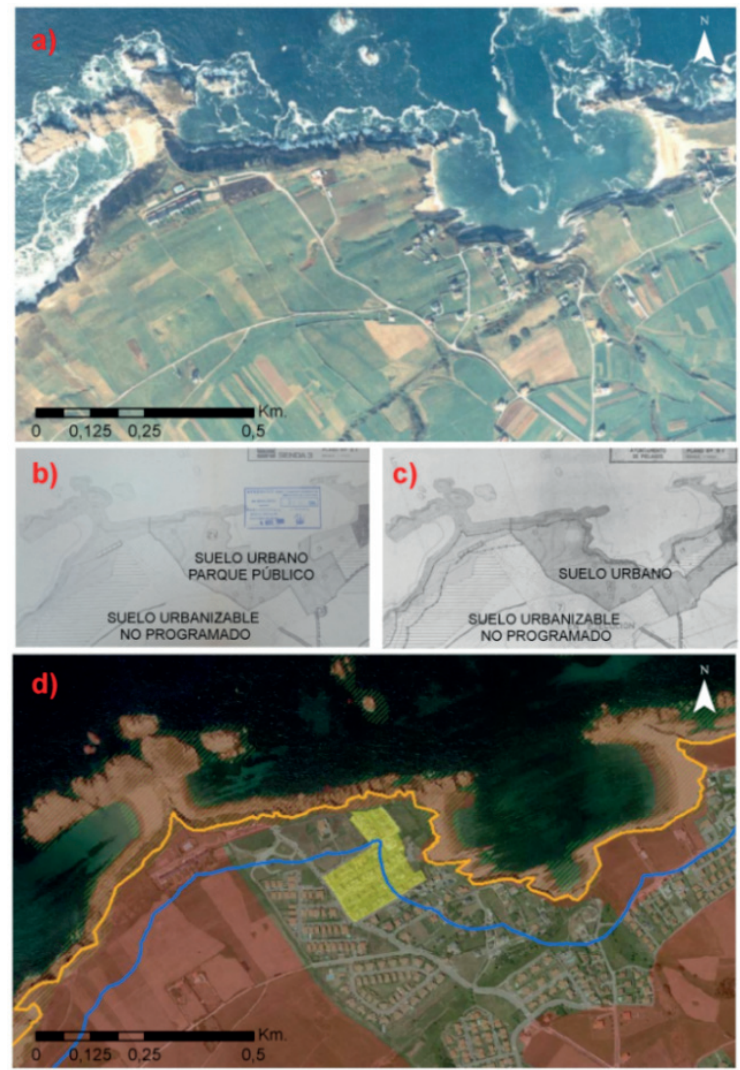

LEYENDA

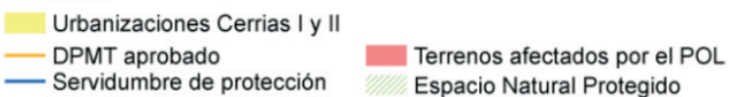

a) Vuelo fotogramétrico del litoral español (año 1988); b) Detalle del plano de clasificación y categorización urbanística del planeamiento urbanístico de Piélagos (Año 1986); c) Detalle del plano de clasificación y categorización urbanística de la modificación del planeamiento urbanístico de Piélagos (Año 1993); Ortofoto perteneciente a la serie del CNIG (Año 2014).

Fuente: Elaboración propia a partir de las ortofotografías del Instituto Geográfico Nacional.

El Plan de Ordenación del Litoral de Cantabria es un instrumento de ordenación territorial destinado a ordenar los usos y proteger los valores medioambientales en el entorno costero de la Comunidad Autónoma. 
Junto con el ejemplo ya mencionado, destacan en el mismo municipio los de las urbanizaciones Cerrias I y Cerrias II (Figura № 3), la urbanización Entrelindes y las 21 viviendas de la unidad de ejecución L-05. En el primer caso, las urbanizaciones fueron construidas parcialmente dentro de la servidumbre de protección del Dominio Público Marítimo Terrestre (DPMT) ${ }^{7}$. La construcción de estas viviendas se produjo en atención a una modificación puntual de su planeamiento urbanístico que pretendía tener carácter retroactivo y que además iba en contra de la legislación estatal de protección de costas. El TS, como consecuencia de esta localización, dictaminó en el año 2012 el derribo de estas edificaciones.

Por otro lado, las reclasificaciones irregulares de suelo han llevado a decenas de viviendas a ser condenadas al derribo. Este es el caso de las 20 viviendas de la Urbanización Entrelindes (en la que además el planeamiento territorial y urbanístico realiza zonificaciones contradictorias) y las 21 viviendas de la unidad de ejecución L-05. Con éstas, la suma de todas las sentencias de demolición contra viviendas ilegales en el municipio se eleva a 480.

En esta deshonrosa clasificación le sigue el municipio costero de Argoños, situado en la zona oriental, con 255 viviendas pendientes de derribo. Dentro de este término municipal destacan las urbanizaciones de La Llana, Pueblo del Mar, y Las Llamas I y II. En los dos primeros casos, las urbanizaciones están construidas dentro de los límites de un espacio natural protegido. Tras las sentencias condenatorias, la Administración ha propiciado cambios en la categorización de ambos terrenos dentro del instrumento de gestión del espacio natural, lo que supone una perversión del planeamiento para intentar salvar del derribo a estas viviendas. Sin embargo, esta solución no parece definitiva a tenor del recurso de inconstitucionalidad, todavía no resuelto, presentado por el TSJC contra la Ley $4 / 2013$, de 20 de junio, relativa al régimen jurídico de las autorizaciones provisionales de edificaciones o actuaciones preexistentes. La intencionalidad de este cuerpo legal, según su preámbulo, es evitar "la paradoja de que se podría volver a construir lo que acababa de ser demolido", puesto que las modificaciones introducidas en las figuras de planeamiento y gestión así lo permiten. Esta innovación legislativa no hace más que refrendar la evidente desregulación urbanística que se produce en la región cántabra, intentando subsanar errores (cuando no ilegalidades) por la vía de la modificación de instrumentos de planificación y gestión con incidencia en el urbanismo, dotándoles de un carácter retroactivo en contra de todo ordenamiento jurídico.

La afección al paisaje y la ocupación de terrenos protegidos por la planificación urbanística ha producido la acumulación de sentencias de derribo (37) para algunas de las edificaciones que componen las urbanizaciones de Las Llamas I y II (de 19 y 22 viviendas respectivamente), Pepín Cano $^{8}$, SATEC, Santiago Martínez Isla y Munargo. Sin embargo, este proceso se ha visto dilatado en el tiempo por la ausencia de ofertas en el concurso público para la adjudicación de los trabajos de demolición (en parte por la presión de los propietarios), lo que ha llevado al TSJC a adjudicar éstos a una empresa pública, iniciando los trámites para la ejecución subsidiaria de las sentencias.

En España, el Dominio Público Marítimo Terrestre es una franja costera de titularidad pública que comprende la protección de los elementos incluidos en ella.

8 En esta urbanización se ha procedido a la demolición de una de las cinco viviendas que la componen. En concreto se trata de la única estructura inacabada y, por lo tanto, deshabitada del conjunto. 
El municipio de Arnuero, con 144 viviendas condenadas al derribo, es el tercero con mayor afectación por urbanismo ilegal en Cantabria. Todas estas construcciones se localizan en la Urbanización El Encinar, incluida en una zona protegida por el POL. En ella sólo se demolieron 42 apartamentos inacabados, cuyo derribo fue adjudicado a la misma empresa promotora, que tras realizar su ejecución, reclamó además el pago del trabajo y el de las indemnizaciones pertinentes a la Administración. Además, los propietarios de las viviendas, a través de Asociación de Maltratados por la Administración (AMA), han conseguido que el TSJC ordene a las administraciones el pago de indemnizaciones por los daños morales provocados. Esta resolución ha sentado jurisprudencia, lo que implica un fuerte impacto económico para las arcas municipales y regionales.

En el municipio de Miengo, las 110 viviendas condenadas al derribo se dividen en dos actuaciones, la Urbanización Playa Marzan de Cuchía y la Licencia a la Inmobiliaria ASVA, S.L., de 20 y 90 viviendas respectivamente. En el primero de los casos, los cambios acaecidos en la delimitación del DPMT han ido alterando la situación legal de esta urbanización. No obstante, según los últimos datos del año 2014, la Audiencia Nacional ${ }^{9}$ volvió a incluir estos terrenos en la zona de afección sectorial de protección de costas, lo que conlleva la ratificación de la condena. En el caso del conjunto de viviendas de la Inmobiliaria ASVA, S.L. la sentencia que anula la licencia se basa en la ocupación irregular de "suelo no urbanizable", por lo que la innovación del instrumento de planeamiento para ajustarlo a las características de la edificación consumada es la única solución posible a este caso.

En definitiva, la fuerte presencia del problema en la vida pública, obliga al gobierno autonómico a anunciar soluciones que nunca llegan. En la actualidad, tras múltiples sentencias de derribo (algunas con más de 20 años de antigüedad), las medidas del Gobierno de Cantabria, como su Plan de Derribos, son hoy papel mojado por su escasa ejecución.

\section{Ocupación edificatoria del "suelo no urbanizable". El caso extremeño}

Extremadura es un vasto territorio de $41.634 \mathrm{~km}^{2}$ y 1.087 .778 habitantes ( 1 de enero 2016), muy poco poblado $\left(26,13 \mathrm{hab} . / \mathrm{km}^{2}\right)$, donde el $59,5 \%$ de la población reside en municipios que no alcanzan los 20.000 habitantes, e incluso más de un $20 \%$ vive en pueblos menores de 2.000 habitantes. El subdesarrollo económico y el actual estancamiento demográfico no han impedido el crecimiento artificial de la superficie destinada a uso residencial. Si bien es cierto que el nivel de artificialización de Extremadura no es comparable con otras zonas de España, sí es relevante cómo y dónde se ha producido parte de ese incremento. Mientras algunos núcleos urbanos permanecen estancados, con una ínfima expansión urbanística, el resto del suelo en sus términos municipales está salpicado por edificaciones residenciales no siempre ajustadas a la legalidad.

Extremadura, por sus características socioeconómicas, no ha sido un centro receptor de población, al menos de origen nacional, por lo que su crecimiento urbanístico emana de sus propios habitantes y de los emigrantes retornados, ya sea por periodos vacacionales cortos (fines de semana) o largos (verano o retornos definitivos de personas jubiladas). Esto explica que podamos encontrar pequeños pueblos, de apenas unos centenares de habitantes, con un alto grado de edificación del "suelo no urbanizable". De forma general, las viviendas son autopromovidas (en ocasiones incluso

La Audiencia Nacional es un tribunal español con jurisprudencia en todo el territorio estatal. 
sin ayuda profesional) sobre parcelas propias, que pueden conservar parte de su anterior destino como explotaciones agrícolas para el autoconsumo o para guardar el ganado. La densidad de las mismas aumenta a medida que nos acercamos al SU, pues es en las coronas periféricas al núcleo donde el parcelario se encuentra más atomizado y existen más infraestructuras viarias y de servicios. Este proceso incontrolado produce un cerco del núcleo, cuyo potencial crecimiento legal se ve condicionado por la preexistencia de edificaciones irregulares, las cuales dejan espacios intersticiales que poco a poco se van rellenando, a razón de una vivienda por parcela.

Existen otros elementos que pueden actuar como focos de atracción de viviendas, como pueden ser las láminas de agua, espacios con buena conexión viaria o enclaves de alto valor paisajístico, aunque también encontramos espacios carentes de todas estas particularidades en los que, pese a ello, existen conjuntos de viviendas unifamiliares irregulares. Esto confirma las dificultades para controlar un problema que se basa en las decisiones individuales, discrecionales y arbitrarias de los propietarios, posiblemente asentadas en una particular concepción del significado de la propiedad privada. La expansión por contagio de las edificaciones puede provocar el nacimiento de una nueva agrupación de viviendas de carácter irregular, en casi cualquier enclave y momento, si el control de las Administraciones responsables no resulta efectivo.

La inacción del gobierno autonómico y las corporaciones locales en este proceso ha contribuido a que la sociedad infravalore el problema, así como al afianzamiento de éste como práctica habitual y despenalizada. La relación directa entre gestores públicos y ciudadanos en los mini-municipios extremeños nos obliga a reflexionar acerca de la oportunidad de mantener las competencias sobre disciplina urbanística en los Ayuntamientos. La presión de los convecinos puede limitar o retrasar las acciones legales contra la expansión urbana ilegal y clandestina, lo que actúa en detrimento de la solución del problema, en especial sobre el "suelo no urbanizable común" donde los delitos prescriben antes y los derribos son más difíciles de ejecutar. Asimismo, es preciso señalar que las corporaciones locales pertenecientes a pequeños núcleos con grandes términos municipales no tienen los medios, ni técnicos ni económicos, para afrontar la lucha contra la edificación ilegal, por lo que sería necesaria una asunción de competencias por las Administraciones responsables, supramunicipales o regionales, con mayor capacidad.

En materia legal, los cambios acaecidos en Extremadura no han tenido el resultado previsto. De hecho, ningún conjunto de viviendas en la comunidad autónoma ha iniciado los trámites para regular su situación. Aceptar esto supondría reconocer unas obligaciones que los propietarios no están dispuestos a asumir, ya que prefieren mantener el statu quo que les permite seguir disfrutando de sus viviendas sin tener que afrontar el pago de multas, los costes de urbanización y las cesiones obligatorias a la Administración establecidas por la Ley. De otro lado, la construcción de urbanizaciones planificadas sobre "suelo no urbanizable" también ha tenido presencia, aunque minoritaria, en Extremadura. En la ciudad de Cáceres, la legalización de la "Urbanización Residencial Universidad" es una nueva muestra de la utilización del planeamiento para regularizar conjuntos residenciales ilegales. Esta promoción de 549 viviendas se construyó sobre la ladera septentrional de la Sierra de la Mosca, aprovechando la Ley 3/1995, de 6 de abril, de Fomento de la Vivienda en Extremadura, conocida como "Ley del kilómetro", posteriormente derogada por la Ley 15/2001, de 14 de diciembre, del Suelo y Ordenación Territorial de Extremadura (LSOTEX) y otros cuerpos legales. Este texto legal "pre-LSOTEX" facilitaba la reclasificación de "suelo no urbanizable" a SU, siempre y cuando el proyecto estuviera dentro de "una línea cerrada imaginaria situada a un máximo de 1.000 metros" del límite del SU. En 2003, el Tribunal Superior de Justicia 
de Extremadura (TSJEX) devolvió a los terrenos su clasificación como "suelo no urbanizable protegido", decisión ratificada por la sentencia del TS en 2007, por lo que las viviendas eran ilegales y podrían ser derribadas. Sin embargo, el instrumento de planificación urbanística municipal de Cáceres, aprobado definitivamente en 2010, reclasificó esos terrenos como urbanos, recuperando la clasificación obtenida mediante la Ley del kilómetro y restableciendo la legalidad de las viviendas. Este hecho fue recurrido por la Asociación de Vecinos de la Umbría y la Solana de la Montaña, conjunto de propietarios de una de las más antiguas agrupaciones de viviendas ilegales en Extremadura. Éstos consideraban que mediante este procedimiento se les había causado un agravio comparativo, puesto que sus terrenos mantenían la clasificación como "suelo no urbanizable protegido". Sin embargo, el TSJEX dio validez al proceso en 2011, lo cual fue ratificado un año después por el TS.

El caso del Complejo Marina Isla de Valdecañas, ubicado en los municipios de El Gordo y Berrocalejo, es quizá el ejemplo más sangrante, tanto por su dimensión arquitectónica y presupuestaria, como por los terrenos afectados y la atención mediática generada (Salcedo y Campesino, 2015). Que la construcción de un campo de golf con urbanización residencial de lujo aneja (todo un clásico en España) haya propiciado la innovación de planeamiento más fugaz e intensa de toda la región, además de la ya analizada modificación legislativa, da fe del uso interesado de los instrumentos de planificación territorial y urbanística en favor de proyectos privados, donde el interés regional declarado es cuando menos discutible. Sobre el Complejo pesa hoy una sentencia de derribo dictada por el TS en 2014. Mientras tanto, la actividad y la venta de chalés continúan ${ }^{10}$, lo que supone un triunfo más de la teoría de los hechos consumados.

A pesar de la existencia de estos casos puntuales, sería un error identificar el modelo de expansión urbana ilegal sobre el "suelo no urbanizable" en Extremadura con estas urbanizaciones, ya que el problema en esta comunidad autónoma tiene un carácter eminentemente clandestino (es decir, aquellos que no piden permiso de construcción), siendo un hecho casi omnipresente a nivel municipal en la región. Una de las zonas donde se aprecia una mayor presencia de viviendas sobre "suelo no urbanizable" es la comarca de La Vera (Figura No 4). Sus atractivos naturales, paisajísticos y patrimoniales, junto con su localización relativamente cercana a Madrid, la convierten en un enclave llamativo para la construcción de segundas residencias. Se estima que dentro de sus límites alberga más de 2.300 viviendas sobre "suelo no urbanizable", lo que significa 2,5 viviendas ilegales por kilómetro cuadrado. Asimismo, más de un $40 \%$ de estas viviendas se sitúa en el entorno inmediato de áreas naturales protegidas (menos de 500 metros medidos desde su límite exterior) e incluso más de un centenar de ellas rodean (zona de influencia de 1.000 metros) alguno de los cuatro núcleos urbanos protegidos por su valor patrimonial.

La Sierra de Santa Bárbara en Plasencia es otro de los espacios donde la concentración de viviendas es más alarmante. Los inicios de la construcción residencial ilegal sobre la ladera de la montaña se remontan a mediados de los años setenta, lo que ha propiciado que hoy existan en este lugar algo más de medio millar de viviendas que contravienen la legislación urbanística. Desde entonces, este área, muy próxima al núcleo urbano, no ha dejado de sumar viviendas clandestinas o ilegales, algunas de ellas con sentencia firme de derribo. Desde la Administración local y regional se ha impulsado un nuevo instrumento de planeamiento urbanístico municipal, que

10 Diario HOY, 19/09/2015. Isla Valdecañas suma varias condenas por vender chalés durante el proceso judicial. 
Figura $\mathrm{N}^{\circ} 4$

Distribución de viviendas en la comarca de La Vera (Provincia de Cáceres)

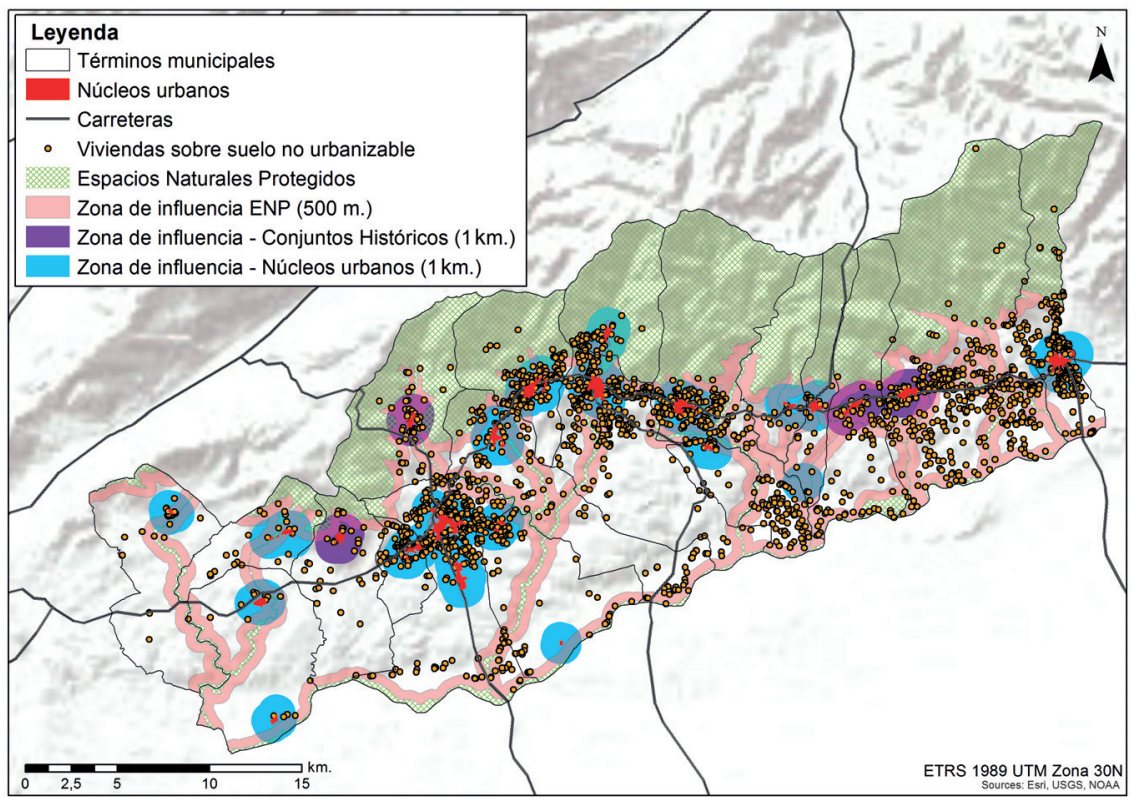

Fuente: Elaboración propia.

contiene una solución parcial del problema, mediante la reclasificación de los terrenos menos elevados a "suelo no urbanizable común", ofreciendo una alternativa para la legalización de las edificaciones, pero dejando un futuro incierto a las viviendas de las cotas más altas, ubicadas en "suelo no urbanizable especialmente protegido".

\section{Contorsionismo normativo para la edificación residencial fuera de los límites urbanos y urbanizables}

En España, las competencias urbanísticas y de ordenación territorial pertenecen a las Comunidades Autónomas desde la promulgación de la Constitución de 1978, lo que abrió la puerta a una mejor adaptación de los textos legales a la realidad de cada territorio, aunque también a una mayor atomización en la clasificación y categorización urbanística del suelo (Alonso, 2012). Sin embargo, no fue hasta el año $2001^{11}$, trascurridos 23 años desde la promulgación de la Carta Magna, cuando las regiones cántabra y extremeña hicieron efectivas sus competencias, a través de un marco urbanístico y de ordenación territorial propio e íntegro. Hasta ese momento, ambas se habían regido por la legislación urbanística estatal y básica. La creación de un marco legislativo propio en Cantabria, mediante la Ley 2/2001, 25 junio, de Ordenación Territorial y Régimen Urba-

La mayor parte de las CC.AA. comenzaron a legislar en materia urbanística y territorial a partir de la Sentencia 61/1997 del Tribunal Constitucional, en la que se reafirma la competencia exclusiva de las regiones españolas para regular estas materias en detrimento del Estado español. 
nístico del Suelo de Cantabria (LOTRUSCA), no contribuyó a solucionar uno de los más importantes problemas urbanísticos de la región, esto es, el desarrollo de la construcción residencial en zonas costeras y cercanas a áreas protegidas. Los instrumentos de ordenación urbanística que esta Ley articula, además de resultar tardíos y limitados, no frenaron un desarrollo inmobiliario que aún fue más acusado tras su publicación por las reticencias de muchos municipios a adaptarse a la nueva norma regional (Delgado, 2011), que en principio resultaba más restrictiva. En Extremadura, la adaptación de la norma a la realidad territorial fue incluso más defectiva, puesto que la LSOTEX se redactó "a imagen y semejanza de las legislaciones valenciana y castellano-manchega" (Campesino, 2010-2: 569), que pertenecen a territorios con dinámicas territoriales y urbanísticas muy distintas a las extremeñas.

Desde el inicio, los cambios en las normativas urbanísticas cántabra y extremeña tuvieron un marcado carácter renovador del régimen del "suelo rústico" y del "suelo no urbanizable". La primera generación de modificaciones legislativas se dedicó en la región cántabra (Ley 2/2009, de 3 de julio) a variar el procedimiento de autorizaciones de construcciones en "suelo rústico", lo que se tradujo en una reducción del periodo de información pública de la solicitud de un mes a quince días, entre otras medidas como la regulación de planes y catálogos específicos para las edificaciones en terrenos rústicos o el aumento de la capacidad de construir viviendas aisladas de carácter unifamiliar en el entorno inmediato al SU. En el caso extremeño, las principales aportaciones de la Ley 9/2010, de 18 de octubre, fueron la inclusión de las disposiciones adicionales cuarta y quinta, dedicadas a regular las urbanizaciones residenciales de carácter autónomo (privado) y urbanizaciones clandestinas o ilegales, respectivamente.

La segunda generación de modificaciones legislativas está protagonizada por las escuetas leyes 2/2011, de 4 de abril en Cantabria y 9/2011, de 29 de marzo en Extremadura. Los cambios que afectaban al territorio cántabro pretendían agilizar los plazos y trámites para determinar la responsabilidad patrimonial de la Administración en caso de derribos de viviendas (especialmente aquellas que constituyeran primera residencia) y otras medidas para aumentar las garantías de los propietarios de las edificaciones. En el caso de Extremadura, la segunda modificación de la LSOTEX sirvió para ceñir la protección ambiental en la planificación urbanística a los entornos que ya tuvieran una protección sectorial reconocida. Sin embargo, en atención a la Sentencia 190/2014 del TS, que declaraba ilegal un proyecto auspiciado por esta modificación, se entiende que esta nueva redacción queda anulada de facto, a pesar de que tal párrafo no ha sido suprimido ni alterado.

Las últimas modificaciones de la LSOTEX (Ley 10/2015, de 8 de abril) y la LOTRUSCA (Ley $3 / 2012$, de 21 de junio) han venido a consolidar una política de flexibilización del "suelo no urbanizable" o "rústico" que se atisbaba desde el primer cambio de los textos legales. Además, tanto el gobierno cántabro como el extremeño han justificado esta mayor laxitud aludiendo al Real Decreto Legislativo 2/2008, de 20 de junio, por el que se aprueba el Texto Refundido de la Ley de Suelo Estatal (RD/TRLS 2008), en una lectura cuando menos interesada de la situación del suelo rural. No obstante, el texto estatal básico define al suelo como "un recurso no sólo económico, sino sobre todo natural, escaso y no renovable" por lo que, "desde esta perspectiva, todo el suelo rural tiene un valor ambiental digno de ser ponderado y su liberalización no puede ampararse en una clasificación indiscriminada del suelo" (Reula y Gavilán, 2011: 15). Sin embargo, en ambos cambios normativos se alude a la necesidad de ampliar los usos permitidos en esta clase de suelo, 
como medida anti-cíclica y manera de preservar y desarrollar el medio rural, inserto en una crisis crónica agravada por el contexto de recesión general.

La tercera modificación de la LOTRUSCA ha enfatizado el papel de los planes específicos para las edificaciones en terrenos rurales regulados en la reforma mencionada anteriormente, como herramienta para construir en esta clase de suelo. No obstante, nuevas alteraciones del texto legal facilitan aún más la construcción de viviendas unifamiliares aisladas, al desvincular su autorización de la existencia de este tipo de planes.

En Extremadura, la tercera modificación de la LSOTEX constituye uno de los cambios más importantes del cuerpo legal con respecto a la regulación del "suelo no urbanizable". Por una parte, sus posibilidades para acoger viviendas aumentan, mientras que por otra, se grava a las construcciones en esta clase de suelo en mayor proporción que al resto. Asimismo, se eliminan las reglas de división, segregación o parcelación de fincas en "suelo no urbanizable", e incluso se descarta la indemnización, en supuestos de reparcelación, para todas las construcciones, incluso aquellas que no hayan sido sancionadas por infracción urbanística grave. Este hecho, unido a la nueva capacitación de la administración autonómica para modificar con mayor facilidad la superficie de la unidad rústica apta para la edificación (superficie mínima de parcela edificable), amplía las posibilidades futuras de una mayor colonización de esta clase de suelo. Por último, una de las medidas con mayor afección territorial es la amnistía para aquellas edificaciones construidas con anterioridad a la Ley estatal urbanística de 1975, siempre que se encuentren en zonas no afectadas por leyes sectoriales y además, no exista riesgo de formación de núcleo de población.

\section{Conclusiones}

Resulta innegable que España está siguiendo un modelo tendente a la desregulación urbanística de los terrenos rurales que ha sentado ya las bases legales para facilitar un aumento del ritmo de depredación del territorio. Tras la liberalización del suelo a finales del siglo XX en España, se produjo una extensión del continuum urbano-rural que devoró extensas superficies situadas alrededor de las grandes metrópolis. La dinámica urbanística positiva y su rentabilidad promovió el salto de los límites legales, lo que conllevó la aparición de crecimientos irregulares sobre la periferia rural de las ciudades. Sin duda, estos espacios ejercen un gran poder de atracción sobre la población urbana gracias a la conservación de sus valores ambientales, que, dentro de un modelo neoliberal, son observados siempre desde una óptica urbanística, y por lo tanto, economicista. Los elementos que ayudaron a proteger estos ámbitos son ahora los que promueven la amenaza transformadora, ya que su presencia crea un alza de los precios de las parcelas. La renta agraria no puede competir con las plusvalías que genera la transformación urbana por lo que se está produciendo una progresiva sustitución de usos productivos por otros residenciales.

La definición residual de los terrenos rurales dentro de la legislación urbanística autonómica española trasladó una concepción de éstos ámbitos como espacios improductivos. Por lo tanto, dentro de este discurso, su transformación urbanística supondría una puesta en valor de los mismos. Si utilizamos los datos que ofrece el SIOSE, el crecimiento medio de la superficie artificial entre los años 2005 y 2011 en los casos estudiados en la región cántabra fue de 43,90\%, mientras que en la región extremeña fue de 116,90\%. Las Administraciones competentes, a pesar de ser 
conscientes de que parte de este crecimiento se realizaba al margen o en contra de la legislación, promovieron cambios dirigidos por una parte a regularizar los crecimientos acaecidos y por otra a flexibilizar el aprovechamiento urbanístico en estos espacios. Las modificaciones legislativas ratificaron el papel de los terrenos rurales como espacios de reserva urbana, lo que anulaba las garantías proteccionistas que ofrecía la zonificación del suelo y la atribución de diferentes regímenes urbanísticos.

Si bien estos crecimientos irregulares no han provocado problemas de segregación socio-espacial, como sí ocurrió en el contexto latinoamericano, la proliferación de viviendas ilegales ha producido un impacto ambiental y territorial debido a la ocupación de espacios protegidos. Por lo tanto, a pesar de encontrarnos en España ante un condicionamiento socioeconómico distinto, ya que son principalmente las clases medias las protagonistas, nos enfrentamos aquí ante un problema legal y ambiental. La participación del grueso socio-económico del país en el proceso multiplica su repercusión espacial, que además viene magnificada por la acción reformista y la inacción disciplinaria de las Administraciones competentes.

Cantabria y Extremadura no han enfrentado un problema que afecta a buena parte de su territorio desde hace décadas. Esto ha permitido que el aumento del número de viviendas fuera de los límites urbanos establecidos por la planificación haya tenido un ritmo pausado y constante, afectando a espacios que, a priori, no tenían un atractivo inmobiliario relevante. En lugar de oponerse frontalmente a la urbanización ilegal del "suelo rústico" y del "suelo no urbanizable", han optado por dilatar la solución del problema, que ha ido ganando en magnitud (impulsado por la bonanza económica de determinados periodos) y complejidad.

Los procesos de urbanización del "suelo rústico" en Cantabria y del "suelo no urbanizable" en Extremadura tienen como denominador común el aumento de la superficie artificial en contra de la legislación sectorial y urbanística. Sin embargo, a pesar de su relativa proximidad, presentan notables diferencias si nos detenemos en cómo, dónde y por qué ha surgido este fenómeno. En Cantabria, la urbanización ha estado muy vinculada a la evolución económica y del sector de la construcción, así como a su potencial turístico y a la fuerte demanda alóctona, procedente del País Vasco (presente en la zona costera oriental) y Madrid (localizada en la zona costera occidental), pero también autóctona, instalada permanentemente (primera residencia) en el área periurbana de Santander, capital autonómica. Por otro lado, en Extremadura, el protagonismo recae sobre los propios habitantes de la región y los emigrantes retornados, que han ocupado paulatinamente el "suelo no urbanizable" con un ritmo desvinculado en mayor medida de la situación económica. La ocupación del "suelo no urbanizable" en España no obedece por tanto a razones de necesidad, bien de tipo particular o colectivo, sino por un afán de ampliar los espacios de ocio sobre la propiedad privada en entornos naturales y/o rurales. En Cantabria, el proceso se ha realizado asemejándose a los crecimientos urbanísticos legales, es decir, de forma planificada, con la participación de empresas promotoras y la construcción de dotaciones y servicios urbanos, en zonas más o menos separadas del núcleo, pero aprovechando espacios atractivos, ya sea por la presencia de la costa o de entornos ambientales bien conservados. Por el contrario, en Extremadura la construcción sobre el "suelo no urbanizable" se ha basado en la clandestinidad a título individual, que en ocasiones ha derivado en grupos de centenares de viviendas dispersas con bajas densidades poblacionales que chocan con el modelo tradicional de asentamiento concentrado. 
Por otro lado, todas las modificaciones legislativas implementadas favorecen la tendencia, cada vez más consolidada, de urbanizar y edificar el medio rural, apoyándose en la hipótesis de que la transformación de esos entornos alimentará su economía. Sin embargo, los desarrollos residenciales, al contrario que los agrícolas, industriales o terciarios, no han dejado un retorno económico duradero. El impacto económico no ha compensado el paisajístico, lo que convierte esta expansión en ineficiente, máxime si tenemos en cuenta la previa existencia de zonas expresamente previstas en la planificación para la urbanización acorde a los parámetros legales (suelo urbanizable). Además, la innovación del planeamiento urbanístico, parte anulada y parte en sede judicial, sólo ha servido para tapar, dando visos de legalidad, los desarrollos irregulares. Las reiteradas sentencias judiciales han evidenciado que el camino tomado por la Administración no fue, ni es, el correcto. La posición soslayada del Ejecutivo extremeño y la cuestionable implicación del Gobierno cántabro es impropia de los garantes de la legalidad. Los gobiernos regionales deben dotarse de más medios para vigilar la expansión urbana irregular y plantear nuevas medidas que detengan a tiempo el proceso, incluyendo una mejor distribución de las competencias en disciplina urbanística.

En España, la polarización de los propietarios de estas viviendas entre víctimas y verdugos, además de reduccionista, carecería de validez para representar todo el conjunto. Sin embargo, debemos reconocer que en el caso extremeño, por las características generales del fenómeno, los propietarios son, o deben de ser, conocedores de las particularidades de su parcela, así como del grado de legalidad de aquellas actuaciones que ellos mismos promueven. La inacción administrativa ha fomentado una sensación de impunidad que favorece la expansión por contagio del problema. En el caso cántabro, los propietarios actuales de vivienda entraron mayoritariamente en el mercado inmobiliario para adquirir su residencia, por lo que fueron ajenos a la promoción de las urbanizaciones. La responsabilidad en este último caso recae mayoritariamente sobre los promotores y administraciones que facilitaron la edificación aun cuando no reunía todos los requisitos legales. De estos dos factores deriva la presencia de un fuerte movimiento vecinal en Cantabria, no presente en Extremadura, por la posibilidad de reclamar indemnizaciones patrimoniales tanto a las empresas promotoras como a la Administración. Los intentos por solucionar el problema han sido un fracaso. Gran parte de las sentencias de derribo no se han ejecutado, a pesar de las reiteradas condenas judiciales procedentes de los Tribunales Superiores de Justicia y del TS. Los errores de la administración cántabra obligan a asumir unos costes de demolición e indemnización, expresados en su Plan de Derribos, pero imposibles de afrontar. En Extremadura, la dispersión del fenómeno dificulta tanto una acción conjunta de confrontación en toda la región, como la vigilancia para mantener la disciplina urbanística. Así, ambos territorios parecen estar abocados a tener que asimilar estos crecimientos tarde o temprano, lo que nos sitúa de nuevo ante escenarios, ya ocurridos en otros países, donde la ciudad ha tenido que digerir e incorporar estos desarrollos espurios dada su magnitud y consolidación.

La consecución de un desarrollo urbano sostenible en ambas regiones pasa por la renovación legislativa, incluso mediante cuerpos legales específicamente dirigidos al "suelo rústico", que establezcan una clara diferenciación entre los usos permitidos y los prohibidos. Para ello, es necesario un planeamiento territorial y urbanístico actualizado, que engarce con las zonificaciones establecidas por la legislación sectorial, la cual debe ser mucho más prolífica y detallada. Si el objetivo es evitar la magnitud de las expansiones urbanas irregulares que están presentes en otros países, se deben acatar las resoluciones firmes de derribo para restablecer la legalidad, fijando un punto y aparte entre la praxis urbanística anterior y la futura. 


\section{Referencias bibliográficas}

AINZ, M.J.; BILBAO, A. y TORRES, R. Dispersión urbana en el Suelo No Urbanizable del País Vasco: la distorsión del planeamiento en la Reserva de la Biosfera de Urdaibai. Estudios Geográficos, 2011, Vol. LXXII, No 271, p. 371-401.

ALONSO, A. Edificación de viviendas en suelo no urbanizable. Práctica Urbanística, 2012, № 117, p. 54-77.

BAUDRILLARD, J. Cultura y simulacro. Barcelona: Editorial Kairós, 1978.

BERRY, B.J.L. Urbanization and counterurbanization. Beverly Hills: Sage Publications, 1976.

BORSDORF, A. e HIDALGO, R. Los Mega-diseños residenciales vallados en las periferias de las metrópolis latinoamericanas y el advenimiento de un nuevo concepto de ciudad. Alcances en base al caso de Santiago de Chile. Scripta Nova. Revista Electrónica de Geografía y Ciencias Sociales, 2005, Vol. IX, No 194 (03). Disponible en Internet: http://www.ub.es/geocrit/sn/sn-194-03.htm

BRAIN, I.; PRIETO, J.J. y SABATINI, F. Vivir en Campamentos: ¿Camino hacia la vivienda formal o estrategia de localización para enfrentar la vulnerabilidad? EURE, 2010, Vol. 36, № 109, p. 111-141.

CAMPESINO, A-J. Ordenación territorial de la Extremadura democrática. Cuadernos Geográficos, 2010-2, Vol. 47, p. 553-581.

CANESTRARO, M.L. ¿llegales, irregulares, informales...?: aportes para un debate sobre el acceso al suelo. Nómadas. Revista Crítica de Ciencias Sociales y Jurídicas, 2013, Vol. Especial, p. 249-370.

CASTAGNA, A.; RAPOSO, I. y WOELFLIN, M. Evolución de los asentamientos irregulares en Rosario. Análisis de una problemática compleja de revertir en el ámbito local. Scripta Nova. Revista Electrónica de Geografía y Ciencias Sociales, 2010, Vol. XIV, № 331 (81). Disponible en Internet: http:// www.ub.es/geocrit/sn/sn-331/sn-331-81.htm

COMISIÓN EUROPEA. Urban sprawl in Europe. The ignored challenge. Copenhagen: European Environment Agency, 2006.

COMISIÓN MUNDIAL SOBRE EL MEDIO AMBIENTE Y EL DESARROLLO. Our common future. New York: United Nations-Oxford University Press, 1987.

CORBOZ, A. El territorio como palimpsesto. En: MARTíN, A. (Editor). Lo urbano en 20 autores contemporáneos. Barcelona: Ediciones de la Universitat Politécnica de Catalunya, 2004, p. 25-34.

DA PENHA, A.; MIKOSZ, R.; RODRIGUES, E. y GARCIA, A. Sensoriamento remoto de alta resolução espacial na caracterização de assentamentos informais. Revista de Geografía Norte Grande, 2014, No 57, p. 143-159.

DE MIGUEL, R. Estado de la periurbanización en Francia: el caso de Nancy. Geographicalia, 1994, No 31, p. 53-69. 
DELGADO, C. Los procesos de difusión urbana en Cantabria. Polígonos. Revista de Geografía, 1999, No 9, p. 71-96.

DELGADO, C. Vivienda secundaria y turismo residencial como agentes de urbanización y segregación territorial en Cantabria. Scripta Nova. Revista Electrónica de Geografía y Ciencias Sociales, 2008, Vol. XII, No 261. Disponible en Internet: http://www.ub.es/geocrit/sn/sn-269.htm

DELGADO, C. La ordenación territorial en Cantabria: Normas, planes, proyectos y realidades. Cuadernos Geográficos, 2010, Vol. 47, p. 453-491.

DELGADO, C. Efectos territoriales, socioeconómicos y legislativos del urbanismo expansivo en Cantabria. En: GOZÁLVEZ, V. y MARCO, J.A. (Editores). Urbanismo expansivo: de la utopía a la realidad. Alicante: XXII Congreso de Geógrafos Españoles, Asociación de Geógrafos Españoles, 2011, p. 203-2016.

ECOLOGISTAS EN ACCIÓN. Banderas negras Cantabria. Santander, 2007.

GAJA i DIAZ, F. Reparar los impactos de la burbuja constructora. Scripta Nova. Revista Electrónica de Geografía y Ciencias Sociales, 2015, Vol. XIX, N 517. Disponible en Internet: http://www.ub.es/ geocrit/sn/sn-517.pdf

GALACHO, F.B. Implicaciones territoriales y aspectos sociales del urbanismo difuso en áreas de transición rural-urbana. Su análisis en la provincia de Málaga (España). En: GOZÁLVEZ, V. y MARCO, J.A. (Editores). Urbanismo expansivo: de la utopía a la realidad. Alicante: XXII Congreso de Geógrafos Españoles, Asociación de Geógrafos Españoles, 2011, p. 267-278.

GARCÍA, L.V. Las pequeñas ciudades en el sistema urbano del Cantábrico oriental. El caso de Castro Urdiales. Evolución y organización del espacio urbano. En: FORTEA, J.I. (Editores). Transiciones. Castro Urdiales y las cuatro villas de la costa de la mar en la historia. Santander: Universidad de Cantabria, 2002, p. 237-251.

GARCÍA-LÓPEZ, M-A. Policentrismo y suburbanización en Barcelona. En: ACE. Architecture, City and Environment = Arquitectura, Ciudad y Entorno. Barcelona: Centre de Política del Sòl i Valoracions - Universitat Politècnica de Catalunya, 2012, Año 6, № 18. Disponible en Internet: http:// upcommons.upc.edu/handle/2099/11681.

GÓMEZ, L.M. La segunda residencia: espacios fragmentados e interconectados. Perspectiva Geográfica. Revista del Programa de Estudios de Posgrado en Geografía, 2010, Vol. 15, p. 113-124.

HIDALGO, R. y ZUNINO, H.M. La urbanización de las áreas periféricas en Santiago y Valparaíso: el papel de las relaciones de poder en el dibujo de la geografía socioresidencial. EURE, 2011, Vol. 37, No 111, p. 79-105.

HIERNAUX, D. y LINDÓN, A. La periferia: voz y sentido en los estudios urbanos. Papeles de Población, 2004, Vol. 10, № 42, p. 1-24. 
JIMÉNEZ, V. y CAMPESINO, A.-J. Los Proyectos de Delimitación de Suelo Urbano y la desprotección del suelo rural en la provincia de Cáceres. En: DE LA RIVA, J.; IBARRA, P.; MONTORIO, R.; RODRIGUES, M. (Editores). Análisis espacial y representación geográfica: innovación y aplicación. Zaragoza: Universidad de Zaragoza, 2015, p. 159-168.

MOSQUERA, R.A. y AHUMADA, A.P. Aspectos de los asentamientos irregulares en América Latina. Revista de arquitectura de la Universidad Católica de Colombia, 2005, № 7, p. 14-16.

NARANJO, G. El rol de la ciudad infiltrada en la reconfiguración de la periferia metropolitana de Santiago de Chile. Estudios Geográficos, 2009, Vol. 70, № 266, p. 205-229.

REULA, L.M. y GAVILÁN, J. El urbanismo ilegal en suelo rural, tratamiento legal y regularización. Práctica urbanística: Revista mensual de urbanismo, 2011, N 104, p. 14-27.

SALCEDO, J.-C. y CAMPESINO, A.-J. Marina Isla de Valdecañas: de Proyecto de Interés Regional a liquidación por derribo. ERÍA, Revista cuatrimestral de Geografía de la Universidad de Oviedo, 2015, No 97, p. 173-188.

VALENZUELA, C.O. Modalidades de expansión en ciudades intermedias argentinas. Urbanización planificada y espontánea en el Gran Resistencia. 1970-1998. Revista de Geografía Norte Grande, $1999, N^{\circ} 26$, p. 85-96.

VARGAS, N.V. El asentamiento irregular como principal fuente de crecimiento urbano en Bolivia: entre ilegalidad y constitucionalidad. América latina hoy: Revista de Ciencias Sociales, 2014, Vol. 68, p. 57-78. 